\title{
NON-LINEAR POST-BUCKLING LARGE DISPLACEMENT ANALYSIS FOR PLANE STEEL NON-PRISMATIC MEMBERS FRAMES WITH FLEXIBLE CONNECTIONS
}

\author{
Hayder Al-Khafaji, NAmeer Alwash ${ }^{*}$ and Sabeeh Al-SarraF ${ }^{* *}$ \\ *Dept. of civil engineering, university of Babylon- Iraq \\ ** Dept. of civil engineering, university of technology, Baghdad-iraq
}

\begin{abstract}
Although the joints constitute a small proportion of the total weight of the structure, but they have a comparatively large work ratio, thus the accounted is represent a large percentage of the total cost of framing. In addition, the contact region deformation is sometimes responsible for a significant proportion of the total deviation of the structure and often has a large impact on the distribution of internal distribution of the forces. All real structures show nonlinear behavior when loads and deformations become large enough and the tapered members are also used in several locations in the structural applications such as aerospace structures, bridges, as well, in many mechanical components. It is used to try to meet the architectural requirements for the shape of buildings and to achieve a suitable division of strength and weight. So, the nonlinear post-buckling behavior of plane steel frame under loads was a major research topic. A general formulation of Eulerian is used to analyze the plane frames and it is clear that this method of analysis are be good to use within theory of beam-column. This study is shown that a polynomial modeling of the non-linear moment-rotation curve of steel connection gives excellent results with the exact non-linear moment-rotation curve with a difference not more than $(1 \%)$ and the effect of the flexible connections must be considered in the analysis because it has significant effect on the behavior of the steel structures and the new modified tangent stiffness matrix which takes into account the two types of non-linearities at the same time (i.e. geometry and connection) and non-prismatic members efficient in giving accurate results of analysis of different types frames with difference not more than $(0.5 \%)$ compere with the other finite element methods for analysis.
\end{abstract}

KEYWORD: large Displacement Analysis, Post Buckling, Flexible Connections, Non-Prismatic Steel Members, Geometrical Nonlinearity.

\section{INTRODUCTION}

A lthough the initial behavior of structural systems can very well be described by a linear modal, all real structures exhibits a pronounced non-linear behavior when the loads and deformations become sufficiently large. However, the entire load-displacement curve of a structure may include both softening and stiffening behavior, the presence of load and displacement limit points and the possible bifurcation of the path. Also, tapered members are used in many structural applications such as highway bridges, space and aircraft structures, as well as, in many mechanical components and machines. It is used in an effort to achieve a better distribution of strength and weight and sometimes to satisfy architectural and functional requirements. Although the joints constitute a small percentage of the price and details of the structure, but they have a relatively large work ratio, thus accounted for a large proportion of the total cost of framing. In addition, contact deformation is sometimes responsible for a large proportion of the total deviation of the structure and often has a significant impact on the distribution of internal strength. Therefore, the nonlinear flexible connections framed behavior under increasing static loads was a major research topic. The large deformation problem of flexible connections frames has been specimen in detail in the references [1, 2 and 5], where a generic wording for the analysis of aircraft frames is presented. It is clear that this method of analysis separates the contribution of solid body deformations from relative organ abnormalities based on beam column theory. The aim of this paper is to extend the previously significant deformation formulation to the analysis of flexible plane frames with flexible nonlinear connectors. 
2. LARGE FORMATION ANALYSIS

\subsection{Force-deformation Relationships}

Consider a non-prismatic member and allow $\{\mathrm{F}\}$ and $\{\mathrm{v}\}$ to denote end-force members and end-displacement respectively in global

$$
\{\mathbf{F}\}=[\mathbf{A}]\{\mathbf{D}\}
$$

in which $\mathbf{D 1}=\mathbf{M 1} ; \mathbf{D 2}=\mathbf{M} 2 ; \mathbf{D 3}=\mathbf{Q L}$

are the local forces.

and the transformation matrix

$$
[\mathrm{A}]=\left[\begin{array}{ccc}
-\frac{\mathrm{e}}{1+\delta} & -\frac{\mathrm{e}}{1+\delta} & \mathbf{w} \\
\frac{\mathrm{w}}{1+\delta} & \frac{\mathbf{w}}{1+\delta} & \mathrm{e} \\
\mathbf{1} & \mathbf{0} & 0 \\
\frac{\mathrm{e}}{1+\delta} & \frac{\mathrm{e}}{1+\delta} & -\mathbf{w} \\
-\frac{\mathbf{w}}{1+\delta} & -\frac{\mathbf{w}}{1+\delta} & -\mathbf{e} \\
0 & 1 & 0
\end{array}\right]
$$

coordinates as shown in Figure (1) and the local coordinates system is used for Eulerian as shown in Figure (2).

The global forces and local forces are related as

[1]:

with

$$
\mathrm{w}=\cos \alpha \quad \mathrm{e}
$$

(4)

The local deformations of members are expressed as:

$$
\begin{aligned}
& \boldsymbol{\theta 1}=\mathrm{v} 3-\rho \\
& \ldots \ldots \ldots \ldots \\
& \boldsymbol{\theta 2}=\mathrm{v} \mathbf{6}-\rho \\
& \ldots \ldots \ldots \ldots \\
& \frac{\mathrm{u}}{\mathrm{L}}=-\delta
\end{aligned}
$$

with

$$
\rho=\alpha-\alpha^{\prime \prime}
$$

$$
\begin{aligned}
& \tan \alpha^{\prime \prime}=\frac{y_{2}-y_{1}}{x_{2}-x_{1}} \\
& \ldots \ldots \ldots \ldots \ldots \ldots \ldots \ldots \ldots \ldots \ldots \ldots \ldots \ldots \ldots \ldots \ldots \\
& \tan \alpha=\frac{y_{2}+L v_{5}-y_{1}-L v_{2}}{x_{2}+L v_{4}-x_{1}-L v_{1}}
\end{aligned}
$$

where $\mathrm{x}$ and $\mathrm{y}$ are the global coordinates of joints in the initial undeformed configuration [1].
The relation of the relative deformities of a member (Figure 2) can be based on beam column theory for flexible members [2]. And so on 


$$
\begin{aligned}
& \mathbf{M}_{1}=\frac{\mathbf{E \mathbf { I } _ { 0 }}}{\mathbf{L}}\left(\gamma_{1} \theta_{1}+\gamma_{2} \theta_{2}\right) \\
& \mathbf{M}_{2}=\frac{\mathbf{E \mathbf { I } _ { 0 }}}{\mathbf{L}}\left(\gamma_{2} \theta_{1}+\gamma_{3} \theta_{2}\right) \\
& \mathbf{Q}=\mathbf{E A}_{0}(\mu-\mathbf{C b})
\end{aligned}
$$

In which;

E : Elasticity modulus,

$\mathrm{I}_{0}$ : Moment of inertia,

$\gamma_{\mathrm{i}}:$ Generalized stability functions,

$\mathrm{A}_{0}$ : Equivalent area of cross section defined by

$$
A_{0}=\frac{L}{\int_{0}^{L} \frac{d x}{A_{(x)}}}
$$

with $\mathrm{A}(\mathrm{x})$ is the variable area of cross section, and

$$
\mu=\frac{\mathbf{u}}{\mathbf{L}}
$$

where $\mathrm{u}=$ relative axial displacement as shown in Figure(2). The length correction factor for bowing action, $\mathrm{Cb}$, is of the form

$$
\mathrm{Cb}=\boldsymbol{\beta}_{1} \cdot \boldsymbol{\theta}_{12}+\mathbf{2} * \boldsymbol{\beta}_{2} \cdot \boldsymbol{\theta}_{1} \cdot \boldsymbol{\theta}_{2}+\boldsymbol{\beta}_{3} \cdot \boldsymbol{\theta}_{22}
$$

In which $\beta \mathrm{i}$ is the generalized bowing functions.

Note: $\gamma \mathrm{i}$ and $\beta \mathrm{i}$ may be viewed as functions of a dimensionless axial force parameter, $\mathrm{q}_{0}$, defined by

$$
\mathbf{q}_{\mathbf{0}}=\frac{\mathbf{Q} \mathbf{L}^{2}}{\pi^{2} \mathbf{E} \mathbf{I}_{0}}
$$

for calculation $\gamma_{\mathrm{i}}$ and $\beta_{\mathrm{i}}$ see Ref. [5].

For the special case of a prismatic member $(\mathrm{EI}=$ constant $)$, one have

$$
\gamma_{1}=\gamma_{3}=\mathbf{C}_{1} \quad ; \quad \gamma_{2}=\mathbf{C}_{2}
$$

and

$$
C_{b}=b_{1}\left(\theta_{1}+\theta_{2}\right)^{2}+b_{2}\left(\theta_{1}-\theta_{2}\right)^{2}
$$

in which $\mathrm{C}_{1}, \mathrm{C}_{2}=$ conventional stability functions of prismatic member and, $\mathrm{b}_{1}, \mathrm{~b}_{2}=$ bowing functions of prismatic member [1].

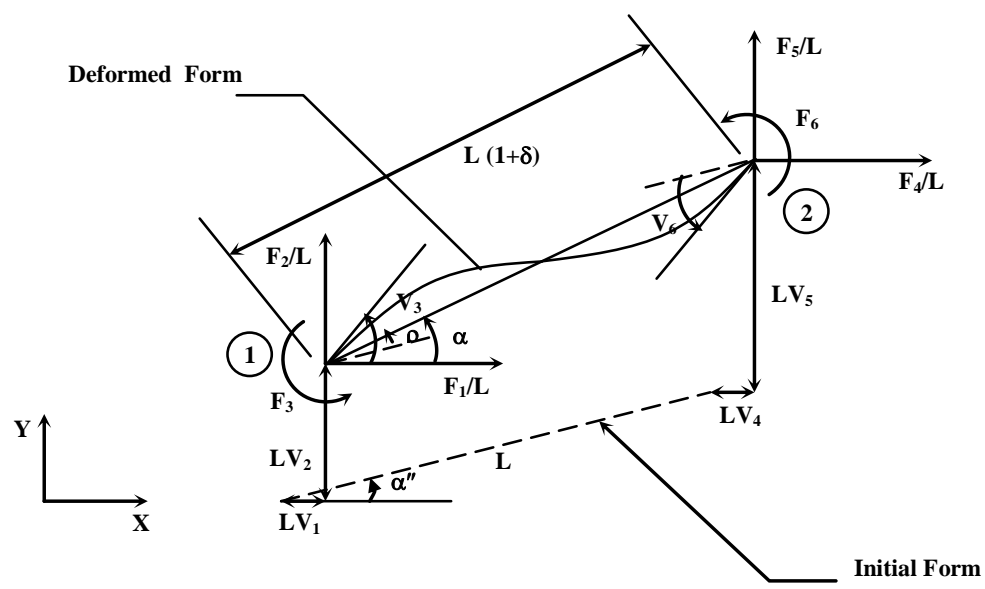

Fig. (1): Member Forces and Deformations in Global Axes . 


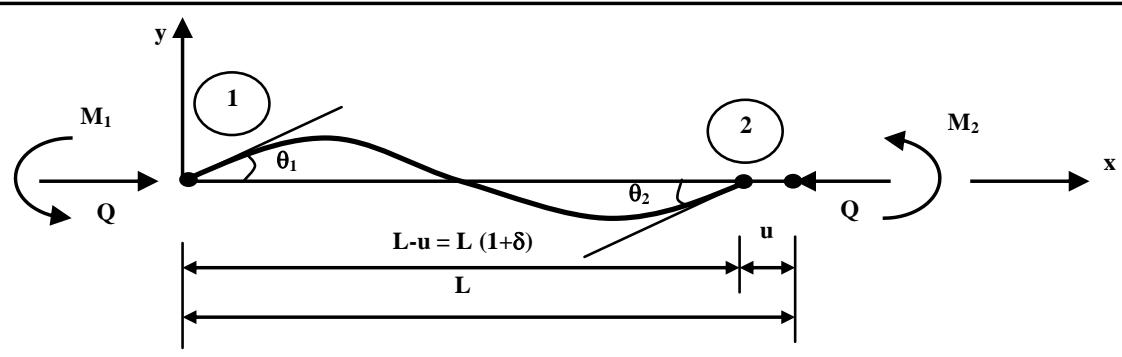

Fig.(2): Local Relative Displacements and Forces for Non-Prismatic Member .

\subsection{Stiffness Matrices For a Member}

The increasing relationship between end-of-member forces and the displacement of end- in global coordinates can be written as follows:

$$
\{\Delta \mathbf{F}\}=[\mathbf{T}]\{\Delta \mathbf{v}\}
$$

in which the member tangent stiffness matrix, [T], is given [2] by

$$
\begin{aligned}
& {[\mathbf{T}]=[\mathbf{A} \llbracket \mathbf{t} \backslash \mathbf{A}]^{\mathrm{T}}+\sum_{\mathbf{k}=1}^{3} \mathbf{S}_{\mathbf{k}}\left[\mathrm{g}^{(\mathrm{k})}\right]} \\
& \{\Delta \mathrm{D}\}=[\mathbf{t}]\{\Delta \mathbf{u}\}
\end{aligned}
$$

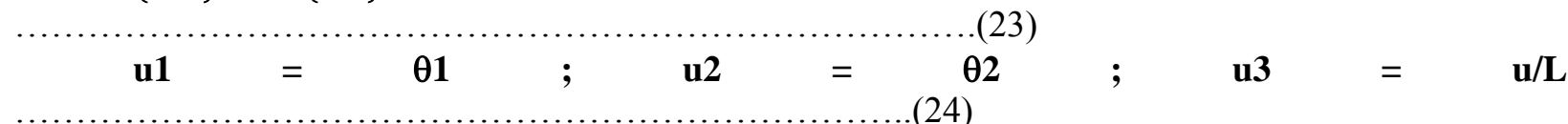

$$
\begin{aligned}
& {[\mathbf{t}]=\frac{\mathbf{E I}_{0}}{\mathbf{L}}\left[\begin{array}{ccc}
\gamma_{1}+\frac{\mathbf{G}_{1}^{2}}{\pi^{2} \mathbf{H}} & \gamma_{2}+\frac{\mathbf{G}_{1} \mathbf{G}_{2}}{\pi^{2} \mathbf{H}} & \frac{\mathbf{G}_{1}}{\mathbf{H}} \\
\gamma_{2}+\frac{\mathbf{G}_{1} \mathbf{G}_{2}}{\pi^{2} \mathbf{H}} & \gamma_{3}+\frac{\mathbf{G}_{2}^{2}}{\pi^{2} \mathbf{H}} & \frac{\mathbf{G}_{2}}{\mathbf{H}} \\
\frac{\mathbf{G}_{1}}{\mathbf{H}} & \frac{\mathbf{G}_{2}}{\mathbf{H}} & \frac{\pi^{2}}{\mathbf{H}}
\end{array}\right]} \\
& \text { with } \quad \mathbf{G}_{1}=-2 \pi^{2}\left(\beta_{1} \theta_{1}+\beta_{2} \theta_{2}\right)=\gamma_{1}^{\prime} \theta_{1}+\gamma_{2}^{\prime} \theta_{2} \\
& G_{2}=-2 \pi^{2}\left(\beta_{2} \theta_{1}+\beta_{3} \theta_{2}\right)=\gamma_{2}^{\prime} \theta_{1}+\gamma_{3}^{\prime} \theta_{2} \\
& \mathbf{H}=\frac{\pi^{2}}{\lambda_{0}^{2}}+\left(\beta_{1}^{\prime} \theta_{1}^{2}+2 \beta_{2}^{\prime} \theta_{1} \theta_{2}+\beta_{3}^{\prime} \theta_{2}^{2}\right) \\
& \lambda_{0}^{2}=\frac{\mathbf{A}_{0} \mathbf{L}^{2}}{\mathbf{I}_{0}}
\end{aligned}
$$

The upper line indicates $\gamma_{\mathrm{i}}$ or $\beta_{\mathrm{i}}$ to the differentiation with respect to $\mathrm{q}_{0}$ (see reference [4]). Engineering matrices, $\quad\left[\mathrm{g}^{(\mathrm{k})}\right]$, are given by

$$
\left[g^{(1)}\right]=\left[g^{(2)}\right]=\frac{1}{(1+\delta)^{2}}\left[\begin{array}{cccccc}
-2 w e & w^{2}-e^{2} & 0 & 2 w e & -\left(w^{2}-e^{2}\right) & 0 \\
w^{2}-e^{2} & 2 w e & 0 & -\left(w^{2}-e^{2}\right) & -2 w e & 0 \\
0 & 0 & 0 & 0 & 0 & 0 \\
2 w e & -\left(w^{2}-e^{2}\right) & 0 & -2 w e & w^{2}-e^{2} & 0 \\
-\left(w^{2}-e^{2}\right) & -2 w e & 0 & w^{2}-e^{2} & 2 w e & 0 \\
0 & 0 & 0 & 0 & 0 & 0
\end{array}\right]
$$




$$
\text { and }\left[g^{(3)}\right]=\frac{1}{(1+\delta)}\left[\begin{array}{cccccc}
-e^{2} & w e & 0 & e^{2} & -w e & 0 \\
w e & -w^{2} & 0 & -w e & w^{2} & 0 \\
0 & 0 & 0 & 0 & 0 & 0 \\
e^{2} & -w e & 0 & -e^{2} & w e & 0 \\
-w e & w^{2} & 0 & w e & -w^{2} & 0 \\
0 & 0 & 0 & 0 & 0 & 0
\end{array}\right]
$$

The member tangent stiffness matrix as described earlier was originally derived by Oran [2].

\section{MODELING OF NON-LINEAR FLEXIBLE CONNECTION}

Flexible connection behavior is usually described by the moment-rotation curves in which the curve slop relates to the rotational stiffness. Several models have been proposed to represent connection behavior. For simplicity, the linear semi-rigid model was used extensively [3], [6], [11]. However, the approximation of a semi-solid linear link is only good when the power at the connection is very small. When the moment of connection is not small, the contact hardness may change significantly compared to the initial hardness and the structure becomes more flexible.

$$
\left.\left.\mathbf{R}_{\mathrm{k}}=\mathbf{R}_{\mathrm{kt}}=\frac{\mathbf{d M}}{\mathbf{d} \phi}\right]_{\phi=\phi}=\frac{\mathbf{1}}{\mathbf{f}_{(\mathbf{m})}^{\prime}}\right]_{\phi=\phi}
$$

And for unloading condition [7]:

$$
\left.\left.\mathbf{R}_{\mathrm{k}}=\mathbf{R}_{\mathrm{ki}}=\frac{\mathbf{d M}}{\mathbf{d} \phi}\right]_{\phi=0}=\frac{\mathbf{1}}{\mathbf{f}_{(\mathrm{m})}^{\prime}}\right]_{\phi=0}
$$

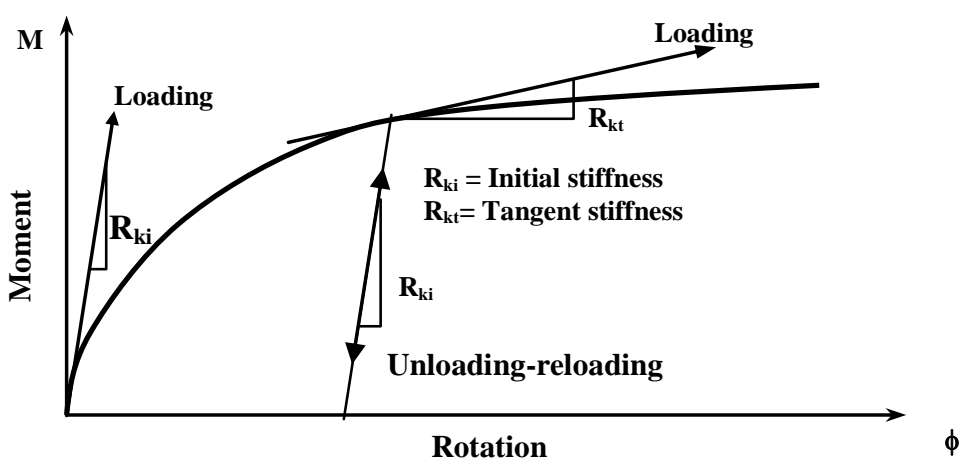

Fig.(3): Loading-Unloading Behavior or Steel Connections .
The non-linear behavior of the flexible connections can be approximated by bilinear or trilinear functions, or expressed by some types of functions, for example, exponential [10] or Ramberg-Osgood [9] functions

In the present study a polynomial expression for connection is

$\phi=\mathbf{a}+\mathbf{b} \cdot \mathbf{M}+\mathbf{c} . \mathbf{M}^{2}+\mathbf{d} \cdot \mathbf{M}^{3}+$

can be used and has a considerable accuracy for the moment-rotation relation [12].

The connection will have different stiffnesses during its loading or unloading conditions Figure (3)) If it is under loading condition then: 


\section{MODIFICATION OF STIFFNESS}

\section{MATRIX}

The incremental force-displacement relationship of a connection can be written as:

$$
\left\{\begin{array}{l}
\Delta \mathbf{M}_{1 \mathrm{cn}} \\
\Delta \mathbf{M}_{2 \mathrm{cn}}
\end{array}\right\}=\left[\begin{array}{cc}
\mathbf{R}_{\mathrm{k}} & -\mathbf{R}_{\mathrm{k}} \\
-\mathbf{R}_{\mathrm{k}} & \mathbf{R}_{\mathrm{k}}
\end{array}\right]\left\{\begin{array}{l}
\Delta \mathbf{v}_{1 \mathrm{cn}} \\
\Delta \mathbf{v}_{2 \mathrm{cn}}
\end{array}\right\}
$$

where $\Delta \mathrm{v}_{1 \mathrm{cn}}$ and $\Delta \mathrm{v}_{2 \mathrm{cn}}$ are the incremental rotational D.O.F. of the connection.

Figure(4) shows the jointed between the variable elements:

(A)
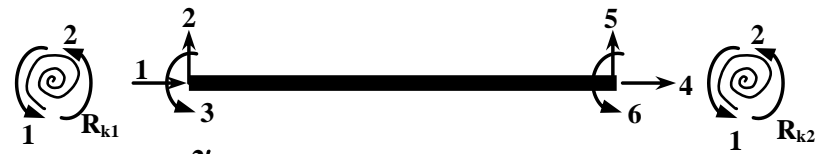

(B)

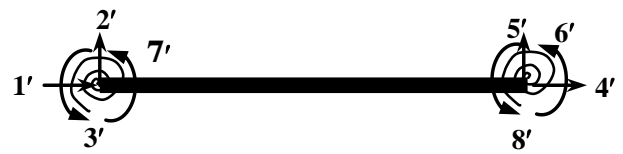

(C)

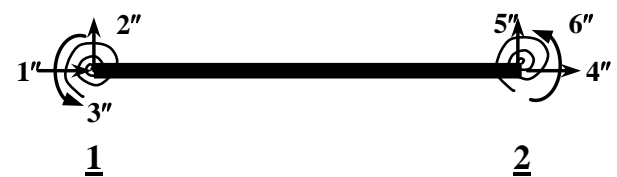

Fig. (4): Beam-Column Element with Presence of Connection.

$$
\left\{\begin{array}{c}
\Delta F_{1} \\
\Delta F_{2} \\
\Delta F_{3} \\
\Delta F_{4} \\
\Delta F_{5} \\
\Delta F_{6}
\end{array}\right\}=\left[\begin{array}{llllll}
k_{11} & k_{12} & k_{13} & k_{14} & k_{15} & k_{16} \\
& k_{22} & k_{23} & k_{24} & k_{25} & k_{26} \\
& & k_{33} & k_{34} & k_{35} & k_{36} \\
& & & k_{44} & k_{45} & k_{46} \\
& & & & k_{55} & k_{56} \\
& & & & & k_{66}
\end{array}\right]\left\{\begin{array}{c}
\Delta \mathbf{v}_{1} \\
\Delta \mathbf{v}_{2} \\
\Delta \mathbf{v}_{3} \\
\Delta \mathbf{v}_{4} \\
\Delta \mathbf{v}_{5} \\
\Delta \mathbf{v}_{6}
\end{array}\right\}
$$

$$
\left[\mathbf{T}_{\mathbf{f f}}\right]=\left[\begin{array}{llllllll}
\mathbf{0} & \mathbf{0} & \mathbf{1} & \mathbf{0} & \mathbf{0} & \mathbf{0} & \mathbf{0} & \mathbf{0} \\
\mathbf{0} & \mathbf{0} & \mathbf{0} & \mathbf{0} & \mathbf{0} & \mathbf{0} & \mathbf{1} & \mathbf{0} \\
\mathbf{1} & \mathbf{0} & \mathbf{0} & \mathbf{0} & \mathbf{0} & \mathbf{0} & \mathbf{0} & \mathbf{0} \\
\mathbf{0} & \mathbf{1} & \mathbf{0} & \mathbf{0} & \mathbf{0} & \mathbf{0} & \mathbf{0} & \mathbf{0} \\
\mathbf{0} & \mathbf{0} & \mathbf{0} & \mathbf{0} & \mathbf{0} & \mathbf{0} & \mathbf{1} & \mathbf{0} \\
\mathbf{0} & \mathbf{0} & \mathbf{0} & \mathbf{1} & \mathbf{0} & \mathbf{0} & \mathbf{0} & \mathbf{0} \\
\mathbf{0} & \mathbf{0} & \mathbf{0} & \mathbf{0} & \mathbf{1} & \mathbf{0} & \mathbf{0} & \mathbf{0} \\
\mathbf{0} & \mathbf{0} & \mathbf{0} & \mathbf{0} & \mathbf{0} & \mathbf{0} & \mathbf{0} & \mathbf{1} \\
\mathbf{0} & \mathbf{0} & \mathbf{0} & \mathbf{0} & \mathbf{0} & \mathbf{0} & \mathbf{0} & \mathbf{1} \\
\mathbf{0} & \mathbf{0} & \mathbf{0} & \mathbf{0} & \mathbf{0} & \mathbf{1} & \mathbf{0} & \mathbf{0}
\end{array}\right]
$$

$$
\left[\mathbf{k}_{\mathrm{CN}}^{\prime}\right]=\left[\mathbf{T}_{\mathrm{ff}^{\prime}}\right]^{\mathrm{T}}\left[\mathbf{k}^{\prime} \mathbf{f}\right]\left[\mathbf{T}_{\mathrm{fr}^{\prime}}\right]
$$

where 


$$
\left[k^{\prime} \mathbf{f}\right]=\left[\begin{array}{ccccccccc}
\mathbf{R}_{\mathrm{k} 1} & -\mathbf{R}_{\mathrm{k} 1} & & & & & & \\
-\mathbf{R}_{\mathrm{k} 1} & \mathbf{R}_{\mathrm{k} 1} & & & & & & \\
& & \mathbf{k}_{11} & \cdot & \cdot & \cdot & \mathbf{k}_{16} & & \\
& & \cdot & & \cdot & & \\
& & \cdot & & \cdot & & \\
& & \cdot & & & \cdot & & \\
& & \mathbf{k}_{61} & \cdot & \cdot & \cdot & \mathbf{k}_{66} & & \\
& & & & & & \mathbf{R}_{k 2} & -\mathbf{R}_{k 2} \\
& & & & & & -\mathbf{R}_{k 2} & \mathbf{R}_{k 2}
\end{array}\right]
$$

$$
\left[k_{\text {gfc }}\right]=\left[T_{\text {f-f-.- }}\right] T\left[k_{\mathrm{CN}}\right]\left[T_{\text {f-f-.- }}\right]
$$

where

$$
\left[\mathbf{T}_{\mathrm{fr}^{\prime \prime}}\right]=\left[\frac{1}{\mathbf{R}_{\mathrm{k}}^{*}}\left[\begin{array}{cc}
\mathbf{k}_{16} \mathbf{k}_{36}-\mathbf{k}_{13}\left(\mathbf{R}_{\mathrm{k}_{2}}+\mathbf{k}_{66}\right) & \mathbf{k}_{13} \mathbf{k}_{36}-\mathbf{k}_{16}\left(\mathbf{R}_{\mathbf{k}_{1}}+\mathbf{k}_{33}\right) \\
\mathbf{k}_{26} \mathbf{k}_{36}-\mathbf{k}_{23}\left(\mathbf{R}_{\mathbf{k}_{2}}+\mathbf{k}_{66}\right) & \mathbf{k}_{23} \mathbf{k}_{36}-\mathbf{k}_{26}\left(\mathbf{R}_{\mathbf{k}_{1}}+\mathbf{k}_{33}\right) \\
\mathbf{R}_{\mathbf{k}_{1}}\left(\mathbf{R}_{\mathbf{k}_{2}}+\mathbf{k}_{66}\right) & \left.-\mathbf{R}_{\mathbf{k}_{1}} \mathbf{k}_{36}\right) \\
\mathbf{k}_{46} \mathbf{k}_{36}-\mathbf{k}_{34}\left(\mathbf{R}_{\mathbf{k}_{2}}+\mathbf{k}_{66}\right) & \mathbf{k}_{34} \mathbf{k}_{36}-\mathbf{k}_{46}\left(\mathbf{R}_{\mathbf{k}_{1}}+\mathbf{k}_{33}\right) \\
\mathbf{k}_{56} \mathbf{k}_{36}-\mathbf{k}_{35}\left(\mathbf{R}_{\mathbf{k}_{2}}+\mathbf{k}_{66}\right) & \mathbf{k}_{35} \mathbf{k}_{36}-\mathbf{k}_{56}\left(\mathbf{R}_{\mathbf{k}_{1}}+\mathbf{k}_{33}\right) \\
\left.-\mathbf{R}_{\mathbf{k}_{2}} \mathbf{k}_{36}\right) & \mathbf{R}_{\mathbf{k}_{2}}\left(\mathbf{R}_{\mathbf{k}_{1}}+\mathbf{k}_{33}\right)
\end{array}\right]^{\mathrm{T}}\right.
$$

in which $[\mathrm{I}]$ is a $6 \times 6$ identity matrix and

$$
\mathbf{R}_{\mathrm{k}^{*}}=\left(\mathbf{R}_{\mathrm{k} 1}+\mathbf{k}_{33}\right)\left(\mathbf{R}_{\mathrm{k} 2}+\mathbf{k}_{66}\right)-\mathbf{k}_{236}
$$

Substitute Equation (38) into Equation (40) to fined:

$$
\left[k_{t}\right]_{\text {mod. }}=\left[T_{\text {ff-f-. }}\right]^{T}\left[T_{\text {ff- }}\right]^{T}\left[k_{\text {ff }}\right]\left[T_{\text {fff-.- }}\right]\left[T_{\text {ff- }}\right]
$$

where $\left[\mathrm{k}_{\mathrm{t}}\right]_{\text {mod. }}$ is the modified element tangent stiffness matrix in global coordinates $[\mathbf{1 3 , 1 4 ]}$.

\section{ANALYSIS PROCEDURE}

The basic hypothesis for the analysis of the iterative is that the correct deflections and internal forces of a structure with nonlinear connections can be obtained from a single linear analysis, provided that the correct flexibility is assumed for each connection. It is now clear that there are two strategies required for successful completion of a single load increase in a iterative method.
1. Selection of a suitable external load increment for the first iterative cycle. The chosen increment is termed an initial load increment and a particular strategy used to determine it is termed a load incrementation strategy.

2. Selection of an appropriate iterative strategy for application in subsequent iterative cycles [ $\mathrm{J} \geq 2]$ with the aim of restoring equilibrium as rapidly as possible. For more details about the post-buckling analysis see Ref.[15, 20].In the application of the criterion of translations and rotation of the joints are treated as separate groups, and the convergence is assumed to have occurred when the inequality 


$$
\left[\frac{\sum_{i=1}^{n}(\Delta v)_{i}^{2}}{\sum_{i=1}^{n}(v)_{i}^{2}}\right]^{(1 / 2)} \leq \operatorname{tol}(0.001)
$$

\section{SLIP ANGLE OF NON-LINEAR FLEXIBLE CONNECTION}

Because of the presence of the connections, the joint rotation and element end rotation are not the same, see Figures (5) and (6).

$$
\left\{\begin{array}{l}
\mathbf{M}_{1} \\
\mathbf{M}_{2}
\end{array}\right\}=\frac{\mathbf{E} \mathbf{I}_{1}}{\mathbf{L}}\left[\begin{array}{ll}
\gamma_{1} & \gamma_{2} \\
\gamma_{2} & \gamma_{3}
\end{array}\right]\left\{\begin{array}{l}
\theta_{1}-\phi_{1} \\
\theta_{2}-\phi_{2}
\end{array}\right\}
$$

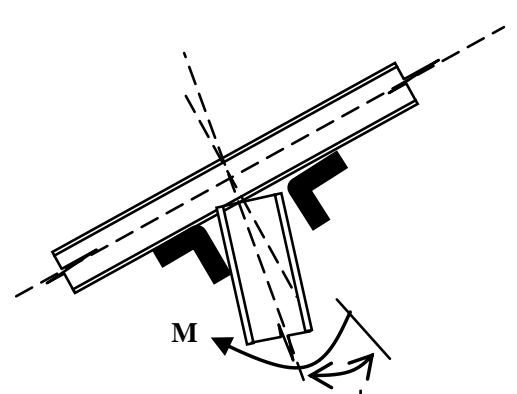

Fig. (5): Slip Angle of a Bearh-Column Connection .

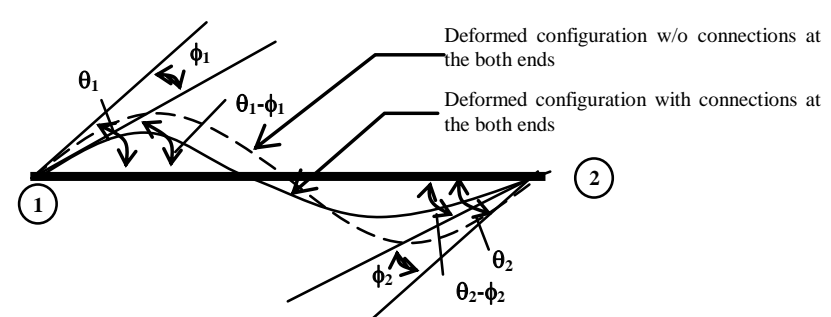

Fig. (6): Beam-Column Element End Rotation In the Present of Connections .

$$
\phi_{1}=\mathbf{f}_{1}\left(\mathbf{M}_{1}\right)
$$$$
\phi_{2}=\mathbf{f}_{2}\left(\mathbf{M}_{2}\right)
$$

Strictly, $\theta_{1}$ and $\theta_{2}$ will be calculated from Equations (5) and (6) and are independent of whether the connection being linear or non-linear.

So, for a member with flexible connections at both ends;

$$
\begin{aligned}
& \mathbf{M}_{1}=\frac{\mathbf{E I _ { 1 }}}{\mathbf{L}}\left(\gamma_{1} \theta_{1}+\gamma_{2} \theta_{2}-\gamma_{1} \phi_{1}-\gamma_{2} \phi_{2}\right) \\
& \ldots \ldots \ldots \ldots \ldots \ldots \ldots \ldots \ldots \ldots \ldots \ldots \ldots \ldots \ldots \ldots \ldots \ldots \ldots \ldots \ldots \ldots \\
& \mathbf{M}_{2}=\frac{\mathbf{E I}}{\mathbf{L}}\left(\gamma_{2} \theta_{1}+\gamma_{3} \theta_{2}-\gamma_{2} \phi_{1}-\gamma_{3} \phi_{2}\right)
\end{aligned}
$$

A substitution of Equations (46) and (47) into Equations (48) and (49) gives 


$$
\begin{aligned}
& \mathbf{M}_{1}=\frac{\mathbf{E} \mathbf{I}_{1}}{\mathbf{L}}\left(\gamma_{1} \theta_{1}+\gamma_{2} \theta_{2}-\gamma_{1} \mathbf{f}_{1}\left(\mathbf{M}_{1}\right)-\gamma_{2} \mathbf{f}_{2}\left(\mathbf{M}_{2}\right)\right) \\
& \mathbf{M}_{2}=\frac{\mathbf{E} \mathbf{I}_{1}}{\mathbf{L}}\left(\gamma_{2} \theta_{1}+\gamma_{3} \theta_{2}-\gamma_{2} \mathbf{f}_{1}\left(\mathbf{M}_{1}\right)-\gamma_{3} \mathbf{f}_{2}\left(\mathbf{M}_{2}\right)\right)
\end{aligned}
$$

assuming two functions:

$$
\begin{aligned}
& \mathbf{F}_{1}\left(\mathbf{M}_{1}, \mathbf{M}_{2}\right)=\mathbf{M}_{1}-\frac{\mathbf{E I}}{\mathbf{L}}\left(\gamma_{1} \theta_{1}+\gamma_{2} \theta_{2}-\gamma_{1} \mathbf{f}_{1}\left(\mathbf{M}_{1}\right)-\gamma_{2} \mathbf{f}_{2}\left(\mathbf{M}_{2}\right)\right)=\mathbf{0} \\
& \mathbf{F}_{2}\left(\mathbf{M}_{1}, \mathbf{M}_{2}\right)=\mathbf{M}_{2}-\frac{\mathbf{E} \mathbf{I}_{1}}{\mathbf{L}}\left(\gamma_{2} \theta_{1}+\gamma_{3} \theta_{2}-\gamma_{2} \mathbf{f}_{1}\left(\mathbf{M}_{1}\right)-\gamma_{3} \mathbf{f}_{2}\left(\mathbf{M}_{2}\right)\right)=\mathbf{0}
\end{aligned}
$$

These two highly non-linear Equations (52) and (53) can be solved using conventional N-R iteration, so that:

$$
\begin{aligned}
& \left\{\begin{array}{l}
\mathbf{M}_{1}^{\mathrm{k}+1} \\
\mathbf{M}_{2}^{\mathrm{k}+1}
\end{array}\right\}=\left\{\begin{array}{l}
\mathbf{M}_{1}^{\mathbf{k}} \\
\mathbf{M}_{2}^{\mathrm{k}}
\end{array}\right\}-\left[\begin{array}{ll}
\frac{\partial \mathbf{f}_{1}^{\mathbf{k}}}{\partial \mathbf{M}_{1}} & \frac{\partial \mathbf{f}_{1}^{\mathrm{k}}}{\partial \mathbf{M}_{2}} \\
\frac{\partial \mathbf{f}_{2}^{\mathbf{k}}}{\partial \mathbf{M}_{1}} & \frac{\partial \mathbf{f}_{2}^{\mathbf{k}}}{\partial \mathbf{M}_{2}}
\end{array}\right]^{-1}\left\{\begin{array}{l}
\mathbf{F}_{1}^{\mathrm{k}}\left(\mathbf{M}_{1}^{\mathbf{k}}, \mathbf{M}_{2}^{\mathrm{k}}\right) \\
\mathbf{F}_{2}^{\mathbf{k}}\left(\mathbf{M}_{1}^{\mathbf{k}}, \mathbf{M}_{2}^{\mathrm{k}}\right)
\end{array}\right\} \\
& \mathbf{E M}_{1}=\left|\frac{\mathbf{M}_{1}^{\mathrm{K}+1}-\mathbf{M}_{1}^{\mathrm{k}}}{\mathbf{M}_{1}^{\mathrm{k}}}\right| \quad, \quad \mathbf{E M}_{2}=\left|\frac{\mathbf{M}_{2}^{\mathrm{k}+1}-\mathbf{M}_{2}^{\mathrm{k}}}{\mathbf{M}_{2}^{\mathrm{k}}}\right|
\end{aligned}
$$

The iteration process continues until both $\mathrm{EM}_{1}$ and $\mathrm{EM}_{2}$ satisfy the convergence criterion simultaneously. The value of $\mathrm{EM}_{1}$ and $\mathrm{EM}_{2}$ is usually in the range $\left(1 \times 10^{-3}-1 \times 10^{-10}\right)[\mathbf{1 3}, \mathbf{2 1}]$. Having $\mathrm{M}_{1}$ and $\mathrm{M}_{2}$ been obtained, $\phi_{1}$ and $\phi_{2}$ can be calculated from Equations (46) and (47) and must be show that in the case of a rigid connection or a real hinge, linear M- $\phi$ relations may be used for these purposes as shown in Figure (7).

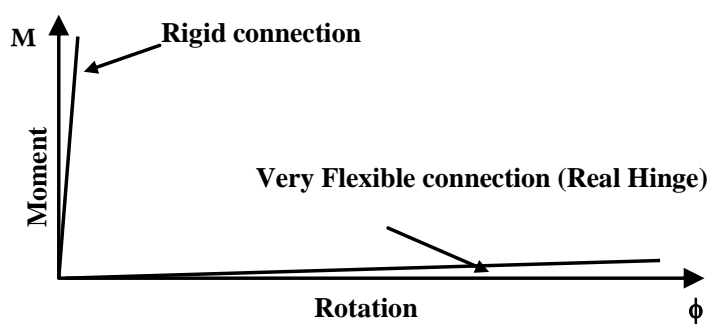

Fig. (7): Linear M- $\phi$ Relations .

In which

$$
\phi=\frac{1}{\mathbf{R}_{\mathrm{k}}} \mathbf{M}
$$

$$
\left.\mathbf{R}_{\mathrm{k}}=\mathbf{R}_{\mathrm{ki}}=\frac{\mathbf{d M}}{\mathbf{d} \phi}\right]_{\phi=\phi}
$$

where $\quad \mathbf{R}_{\mathrm{k}}=\left[\begin{array}{cl}\approx 0 & \text { for pinned connection } \\ \approx \infty & \text { for rigid connection }\end{array}\right.$ 
Noting that $\mathrm{q}_{\mathrm{o}}$ is the only unknown in Equation (14), let [8]:

\section{AXIAL MEMBER FORCE}

$$
\mathbf{k}\left(\mathbf{q}_{0}\right)=\frac{\pi^{2}}{\lambda_{0}^{2}} \mathbf{q}_{0}+\mathbf{C}_{b}-\frac{\mathbf{u}}{\mathbf{L}}=\mathbf{0}
$$

Let $\mathrm{q}_{\mathrm{oi}}$ be an approximate solution of this equation. By using a first-order Taylor series expansion, Equation (59) can be rewritten as

$$
\mathbf{k}\left(\mathbf{q}_{\mathrm{oi}}+\Delta \mathbf{q}_{\mathrm{oi}}\right)=\mathbf{k}\left(\mathbf{q}_{\mathrm{oi}}\right)+\mathbf{k}^{\prime}\left(\mathbf{q}_{\mathrm{oi}}\right) \Delta \mathbf{q}_{\mathrm{oi}}=\mathbf{0}
$$

in which a prime superscript denotes a differentiation with respect to $\mathrm{q}_{\mathrm{o}}$, and

$$
\mathbf{k}^{\prime}\left(\mathbf{q}_{\mathrm{oi}}\right)=\frac{\pi^{2}}{\lambda_{\mathrm{o}}^{2}}+\mathbf{C}_{\mathrm{b}}^{\prime}
$$

A new value is thus obtained for $\mathrm{q}_{\mathrm{o}}$ :

$$
\mathbf{q}_{o i+1}=\mathbf{q}_{o \mathrm{i}}+\Delta \mathbf{q}_{\mathrm{oi}}=\mathbf{q}_{\mathrm{oi}}-\frac{\mathbf{k}\left(\mathbf{q}_{\mathrm{oi}}\right)}{\mathbf{k}^{\prime}\left(\mathbf{q}_{\mathrm{oi}}\right)}
$$

and the iteration continue until

$$
\left|\Delta \mathbf{q}_{\mathbf{o}}\right| \leq \mathbf{e}
$$

In Equations (14) and (67), $\mathrm{Cb}$ and $\mathrm{C}^{\prime} \mathrm{b}$ are given by

$$
\begin{aligned}
& C_{b}=\beta_{1}\left(\theta_{1}-\phi_{1}\right)^{2}+2 \beta_{2}\left(\theta_{1}-\phi_{1}\right)\left(\theta_{2}-\phi_{2}\right)+\beta_{3}\left(\theta_{2}-\phi_{2}\right)^{2} \\
& C_{b}^{\prime}=\beta_{1}^{\prime}\left(\theta_{1}-\phi_{1}\right)^{2}+2 \beta_{1}\left(\theta_{1}-\phi_{1}\right)\left(\theta_{1}^{\prime}-\phi_{1}^{\prime}\right)+2 \beta_{2}^{\prime}\left(\theta_{1}-\phi_{1}\right)\left(\theta_{2}-\phi_{2}\right) \\
& +2 \beta_{2}\left(\theta_{1}^{\prime}-\phi_{1}^{\prime}\right)\left(\theta_{2}-\phi_{2}\right)+2 \beta_{2}\left(\theta_{1}-\phi_{1}\right)\left(\theta_{2}^{\prime}-\phi_{2}^{\prime}\right)+\beta_{3}^{\prime}\left(\theta_{2}-\phi_{2}\right)^{2} \\
& +2 \beta_{3}\left(\theta_{2}-\phi_{2}\right)\left(\theta_{2}^{\prime}-\phi_{2}^{\prime}\right)
\end{aligned}
$$

in which $\theta^{\prime}{ }_{1}, \theta_{2}^{\prime}$ equal to zero for member with connection at both ends and are independent of whether the connection being linear or non-linear, and

$$
\begin{aligned}
& \phi_{1}^{\prime}=\left(\frac{d}{d M_{1}} f_{1}\left(M_{1}\right)\right) \cdot \frac{d M_{1}}{d q_{o}} \\
& \phi_{2}^{\prime}=\left(\frac{d}{d M_{2}} f_{2}\left(M_{2}\right)\right) \cdot \frac{d M_{2}}{d q_{o}}
\end{aligned}
$$

where $f_{1}\left(M_{1}\right), f_{2}\left(M_{2}\right)$ are equation of $M-\phi$ curve, for ends 1 and 2 respectively.

8)

$$
\mathbf{M}_{1}=\frac{E I_{1}}{L}\left[\gamma_{1} \theta_{1}+\gamma_{2} \theta_{2}-\gamma_{1} \mathbf{f}_{1}\left(M_{1}\right)-\gamma_{2} \mathbf{f}_{2}\left(M_{2}\right)\right] .
$$

$$
\mathbf{M}_{1}=\frac{\mathbf{E I}_{1}}{\mathbf{L}}\left[\gamma_{1} \theta_{1}+\gamma_{2} \theta_{2}-\gamma_{1} \mathbf{f}_{1}\left(\mathbf{M}_{1}\right)-\gamma_{2} \mathbf{f}_{2}\left(\mathbf{M}_{2}\right)\right]
$$

to obtain $\left(\phi_{1}^{\prime}, \phi_{2}^{\prime}\right),\left(\mathrm{dM} 1 / \mathrm{dq}_{\mathrm{o}}\right.$ and $\left.\mathrm{dM} 2 / \mathrm{dq}_{\mathrm{o}}\right)$ must be obtained, thus

$$
\begin{aligned}
& \frac{\mathbf{d} \mathbf{M}_{1}}{\mathbf{d} \mathbf{q}_{\mathrm{o}}}=\frac{E \mathbf{I}_{1}}{\mathbf{L}}\left[\gamma_{1}^{\prime} \theta_{1}+\gamma_{2}^{\prime} \theta_{2}-\gamma_{1} \mathbf{f}_{1}^{\prime}\left(M_{1}\right) \frac{\mathbf{d} \mathbf{M}_{1}}{\mathbf{d q _ { 0 }}}-\gamma_{1}^{\prime} \mathbf{f}_{1}\left(M_{1}\right)-\gamma_{2} \mathbf{f}_{2}^{\prime}\left(M_{2}\right) \frac{\mathbf{d} \mathbf{M}_{2}}{\mathbf{d q _ { 0 }}}-\gamma_{2}^{\prime} \mathbf{f}_{2}\left(M_{2}\right)\right] \\
& \frac{\mathbf{d} \mathbf{M}_{2}}{\mathbf{d q _ { 0 }}}=\frac{\mathbf{E I}_{1}}{\mathbf{L}}\left[\gamma_{2}^{\prime} \theta_{1}+\gamma_{3}^{\prime} \theta_{2}-\gamma_{2} \mathbf{f}_{1}^{\prime}\left(\mathbf{M}_{1}\right) \frac{\mathbf{d} \mathbf{M}_{1}}{\mathbf{d q _ { 0 }}}-\gamma_{2}^{\prime} \mathbf{f}_{1}\left(\mathbf{M}_{1}\right)-\gamma_{3} \mathbf{f}_{2}^{\prime}\left(\mathbf{M}_{2}\right) \frac{\mathbf{d M _ { 2 }}}{\mathbf{d q _ { 0 }}}-\gamma_{3}^{\prime} \mathbf{f}_{2}\left(M_{2}\right)\right]
\end{aligned}
$$

Solving the two equations simultaneously, $\frac{\mathbf{d} \mathbf{M}_{1}}{\mathbf{d q}_{\mathbf{0}}} \quad$ and $\quad \frac{\mathbf{d M _ { 2 }}}{\mathbf{d q _ { 0 }}}$ are obtained.

\section{FLOW CHART FOR ANALYSIS}

Present program consists of a main routine and many subroutines. Each one of this subroutine has been designed to deal with a part of the analysis and that part may be repeated more than one time in the main routine. The flow chart of the main routine will be given here only. The purpose of the main routine is to control and arrange the process in the program. In other words the subroutines will work together under the organization of the main routine. A flow chart which represents the sequence of the operations in this routine is shown in

Figure 


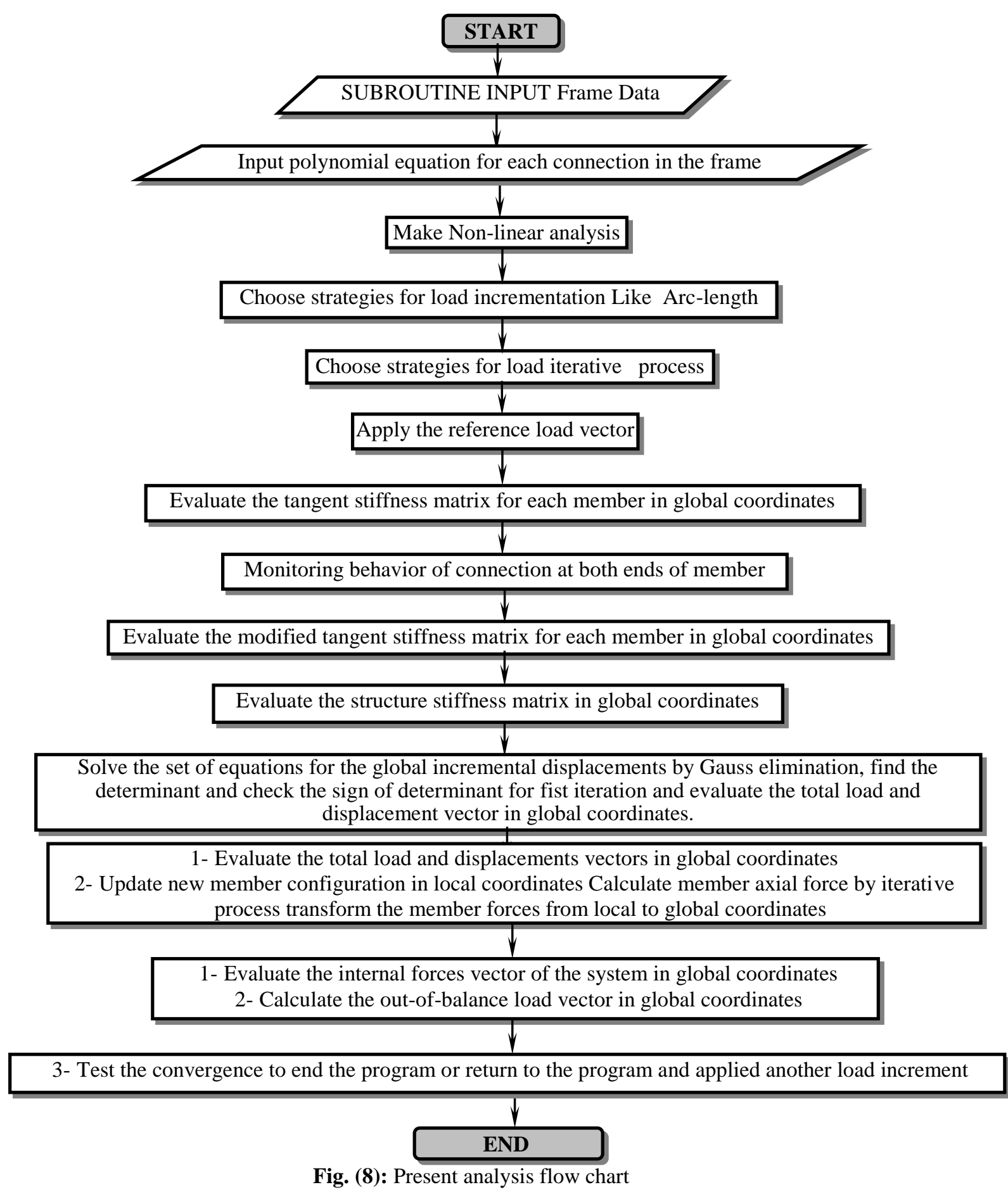

\section{a. Flat Sine Arch}

\section{NUMERICAL EXAMPLE}

This Flat Sine Arch example has been used to display the post-buckling analysis for plane frame. Figure (9) shows the sine shape of a curve and it is centrally concentrated vertical load $(F)$. It is assumed that a continuously curving arch can be represented by a collection of straight elements. Haisler and Stricklin [4] analyzed this example using finite element method. They used displacement-load incrementation procedure in conjunction with the self-correction or Newton- 
Raphson methods for predicting pre- and postbuckling response.

Wong and Tin-Loi [16] analyzed this arch using four-elements model for half of this symmetrical arch. They used the incrementaliterative method with a load step of $1780 \mathrm{~N}$ at initial stages. As the limit point was approached, the solution procedure automatically switched to the reduced modified arc-length method at a load of $10680 \mathrm{~N}$, finally stopping at a load of $13278 \mathrm{~N}$, which was considered to be the limit point load.

The load-displacement curve is shown in Figure (10), this Figure shows that the obtained points on the path became very close near the extremum points and vice versa. However, good agreement is obtained with the solutions obtained by other researchers

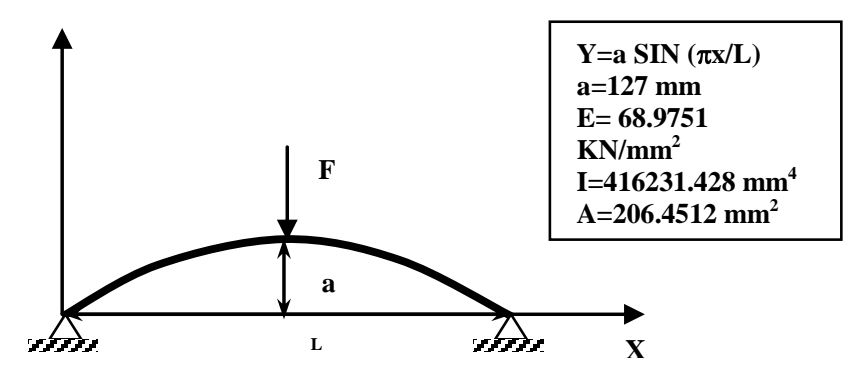

Fig. (9): Shallow Arch (Geometry and Loading Conditions) .
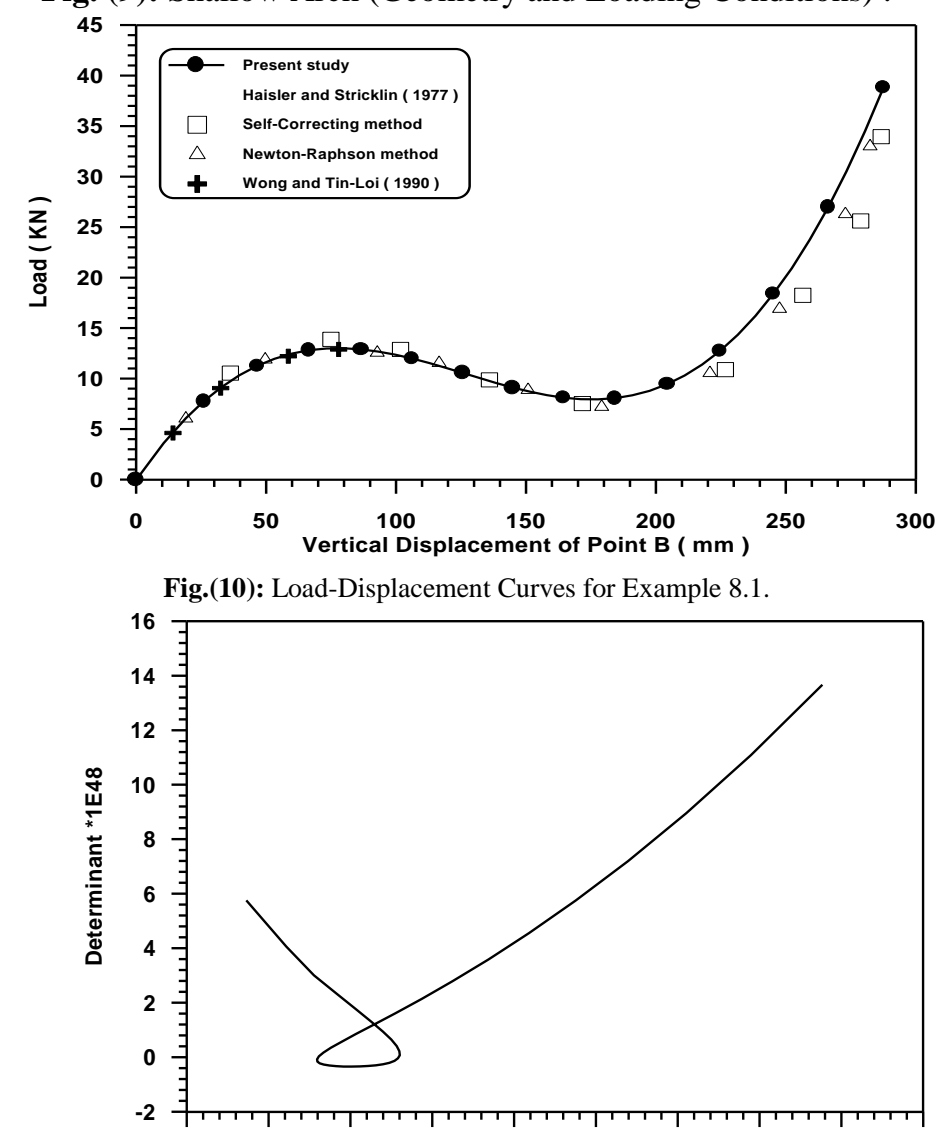

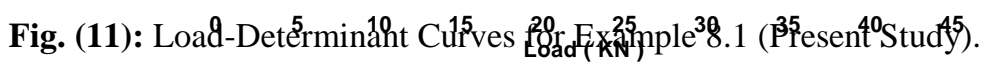

\section{b. Portal Frame with Tapered Members}

Figure (12) shows the geometry and loading conditions for Portal Frame example. This case considers a portal frame with tapered columns. The non-prismatic member can be represented by a number of prismatic elements which is considered as the second method of solution while the first method of results is the solution by representing the non-prismatic member as a one tapered element. Figure (13) shows the load- 
displacement curve for horizontal displacement of point B. This Figure shows that the results based on the second method approaches more and more to the solution obtained by first method when the number of elements is increased. This confirms that the first method is very efficient and accurate. For large structures, the required memory and the computation time become very important especially when the structure contains nonprismatic members. As can be seen the representation of the non-prismatic member by using number of prismatic elements requires large memory and computation time. In the present example, the solution based on the first method requires only 15 second while the solution based on the second method using 2, 4 and 8 prismatic elements for each column requires 19 second, 27 second and 121 second respectively. This difference also confirms the efficiency of the first method. The present case is solved by using the arc-length load incrementation strategy and the minimum residual displacement iterative strategy or with the arc-length iterative strategy. AlUraiby[19], also solved this example.

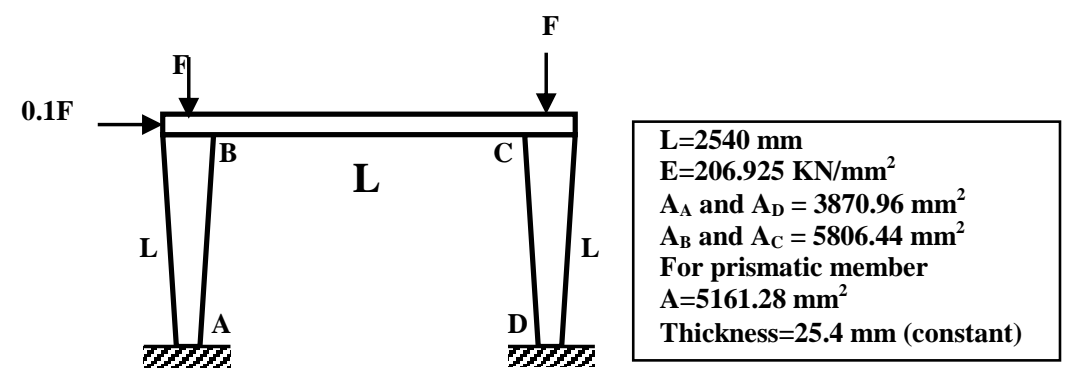

Fig. (12): Geometry and Loading Conditions for Example 8.2 .

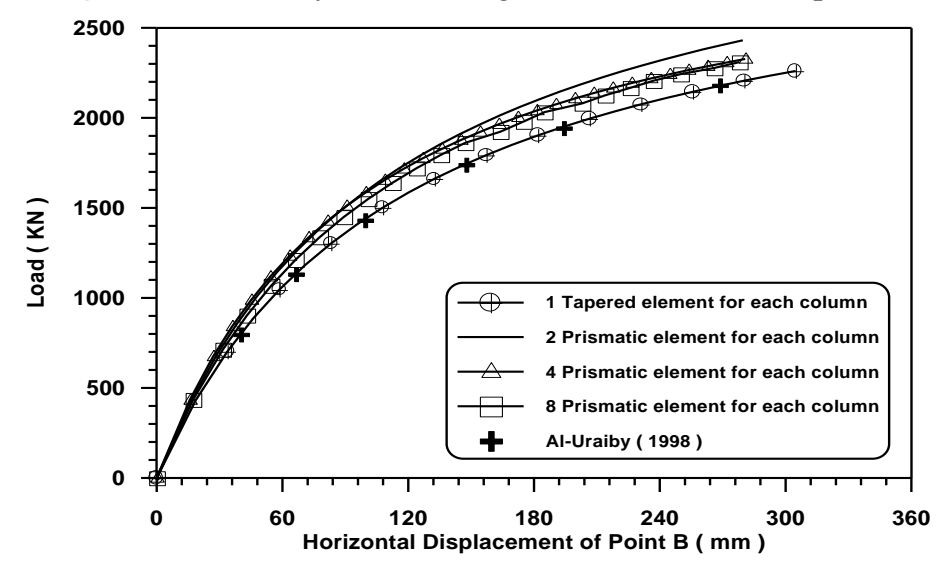

Fig. (13): Load-Displacement Curves for Example8.2 .

\section{c. William's Toggle Frame}

Figure (14) shows the Shape, properties and loading of the William switch frame. Figure (14) shows the behavior of a toggle with nonlinear elastic support with the behavior shown in figure (15). For comparison purposes, the figure also shows a switching behavior with rigid and flexible support [17]. It can be observed that before the first limit point, the load deviation behavior of the switch with a single rigid support with a fully flexible support is fully comparable. When or after the first border point, however, a switch with flexible support deviates much more. 

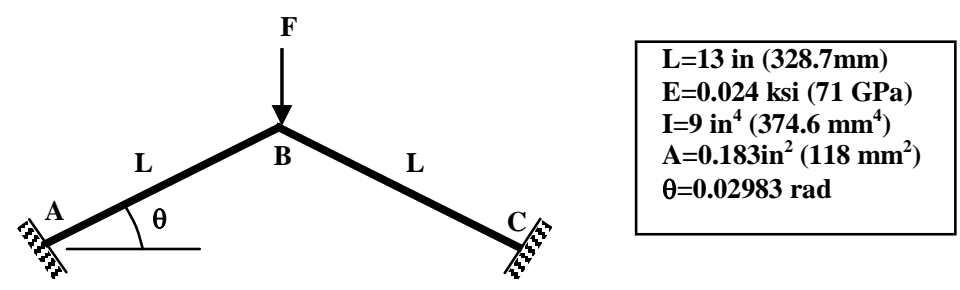

Fig. (14) : Toggle Frame (Geometry and Loading Conditions) .

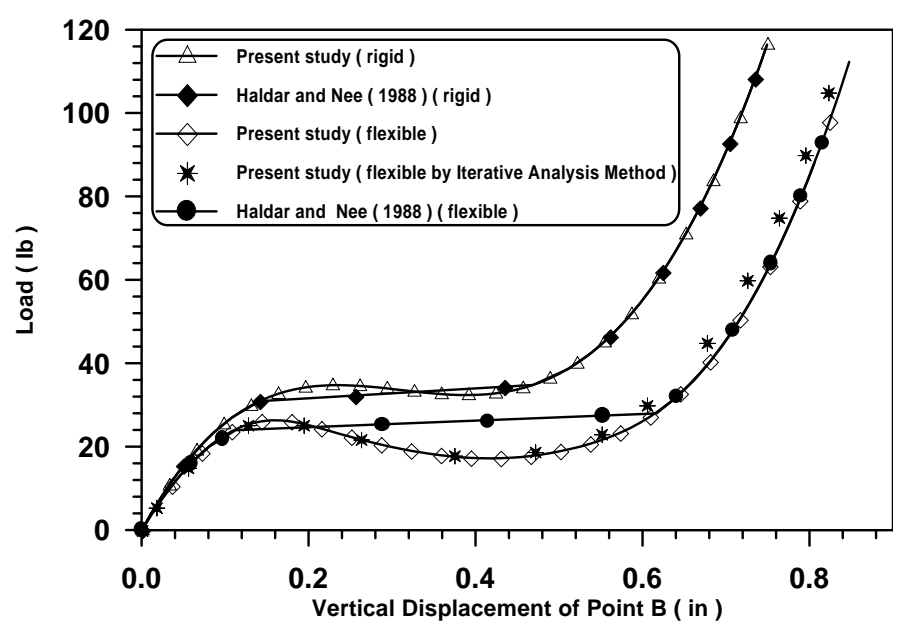

Fig. (15): Load-Displacement Curves for Toggle Frame .

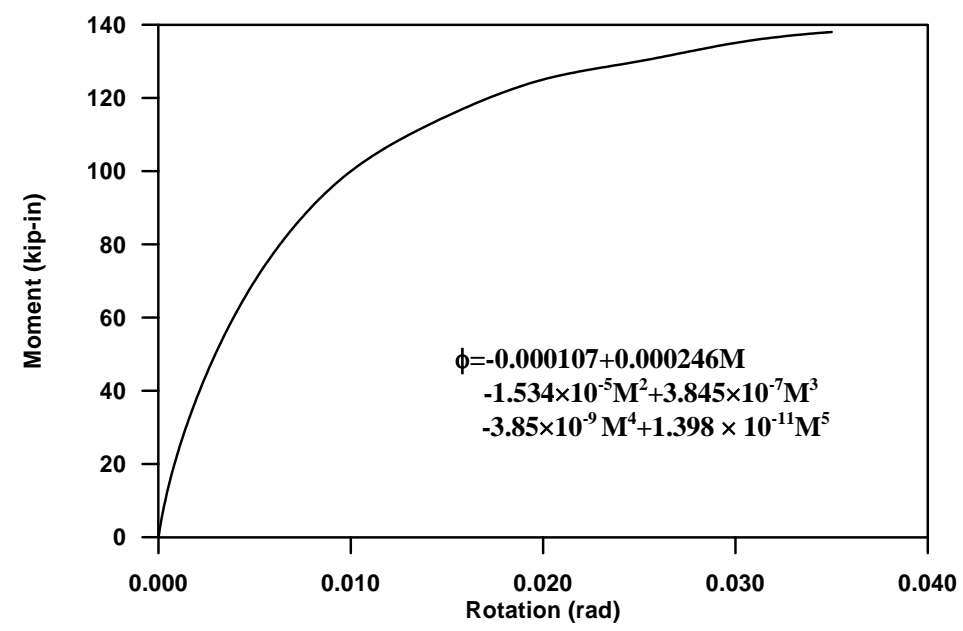

Fig. (16): Moment-Rotation Behavior Used for Supports of Toggle Frame .

\section{d. Four Story Frame}

The geometry, properties and loading conditions for the one bay four story frame are shown in Figure (17). The Frame had also been analyzed by Al-Sadder (1994) [18], the momentrotation behavior shown in Figure (18). 


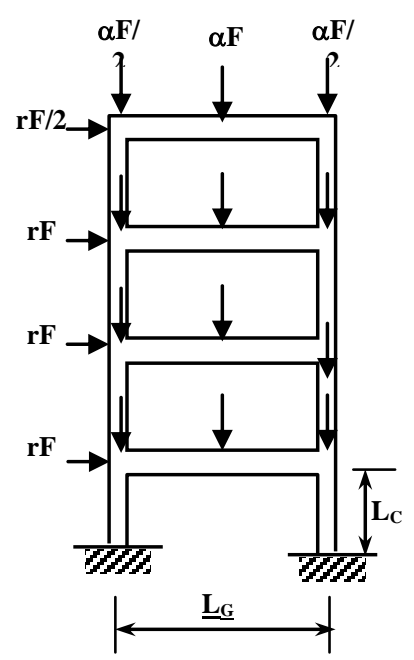

(a)

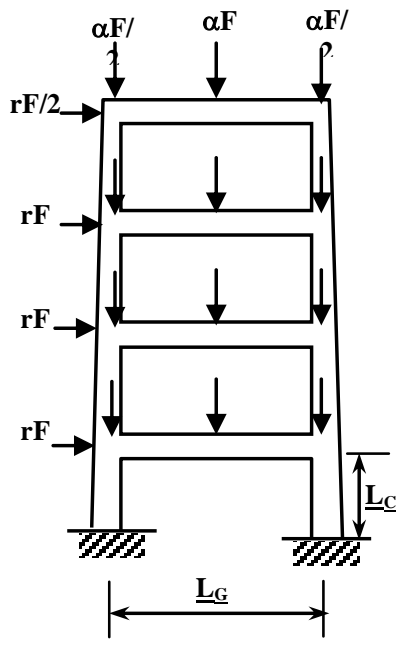

(b)

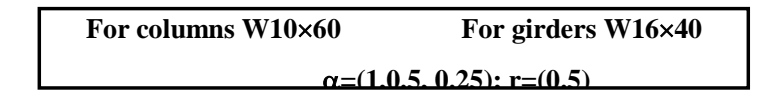

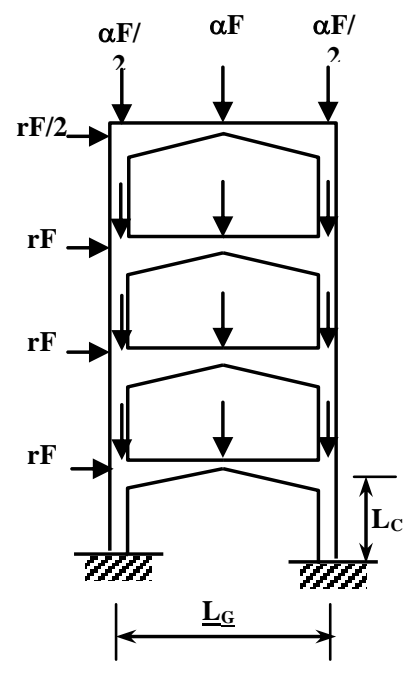

(c)

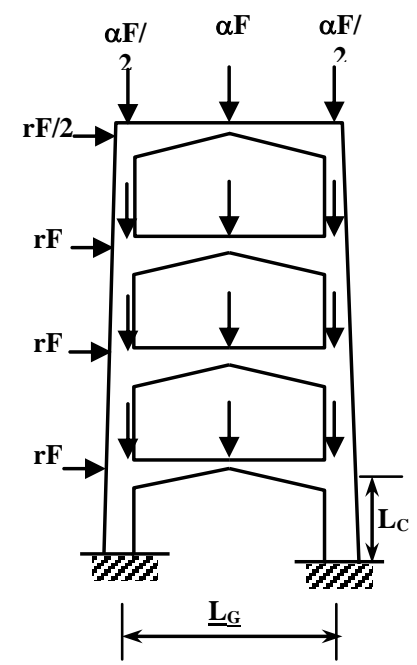

(d)

Fig. (17) : Four Story Frame (Geometry and Loading Conditions) .

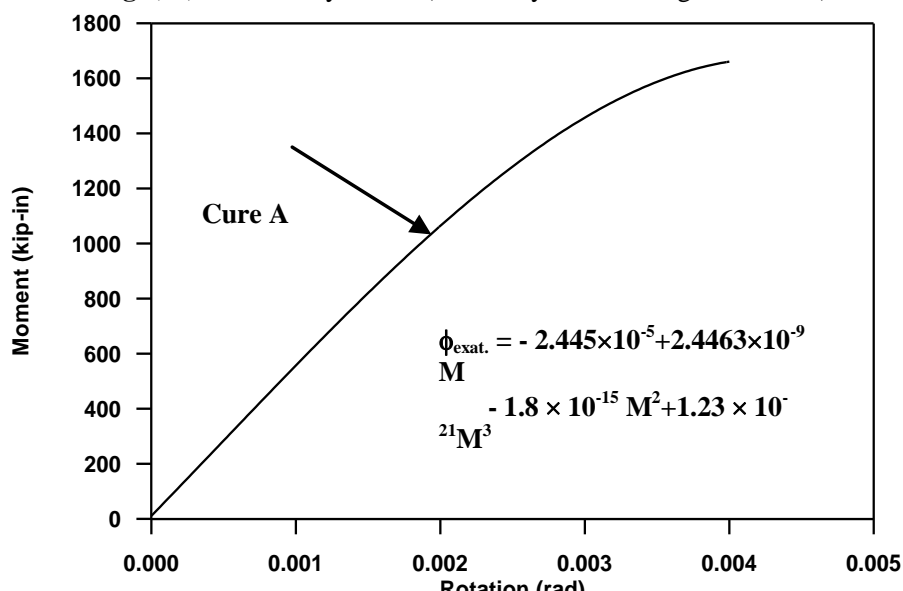

Fig. (18): Moment-Rotation Behavior Used for Four Story Frame . 

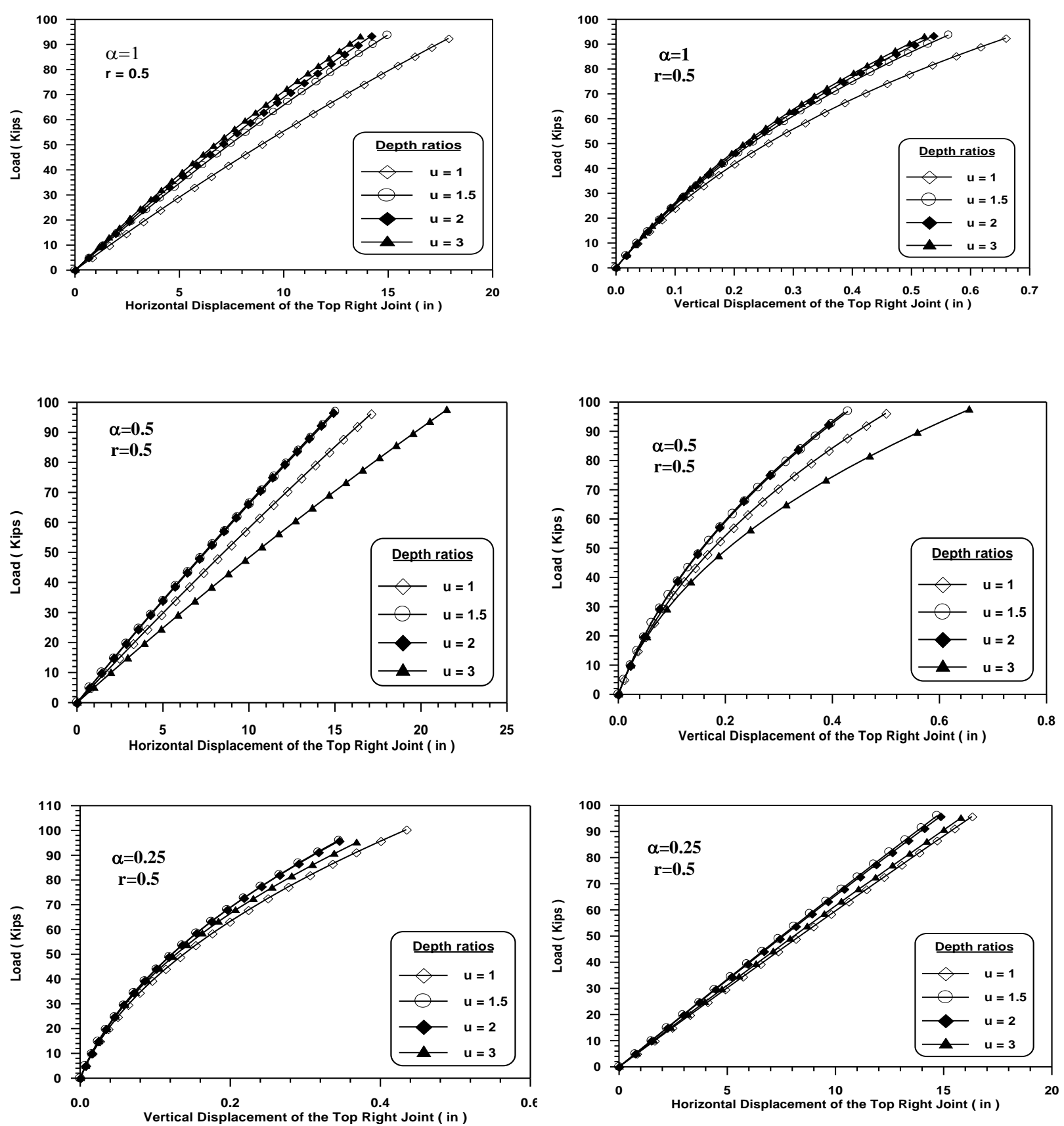

Fig. (19): Load - Displacement Behavior Used for Four Story Frame Case a\&d (Rigid Joint).

$\alpha=1$

$\alpha=1$

$\mathrm{r}=0.5$

$\mathrm{r}=0.5$ 

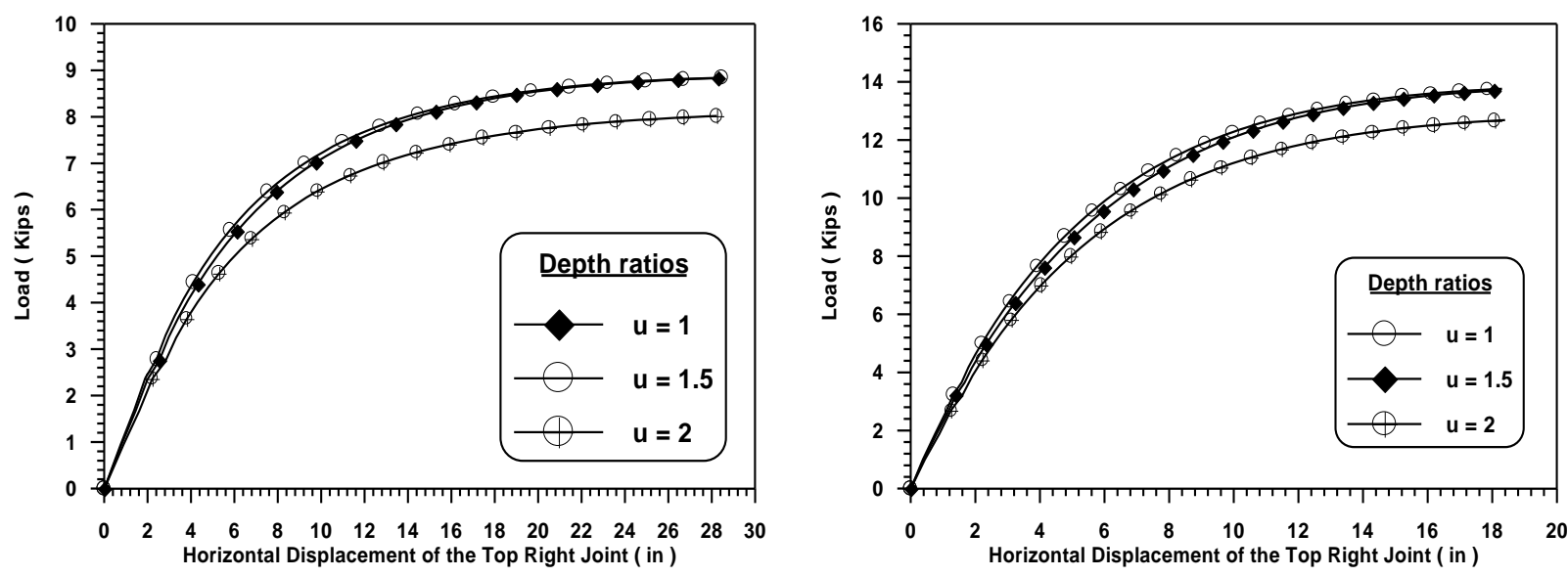

Figure (20): Load - Displacement Behavior Used for Four Story Frame Case a\&d (Flexible Joint).
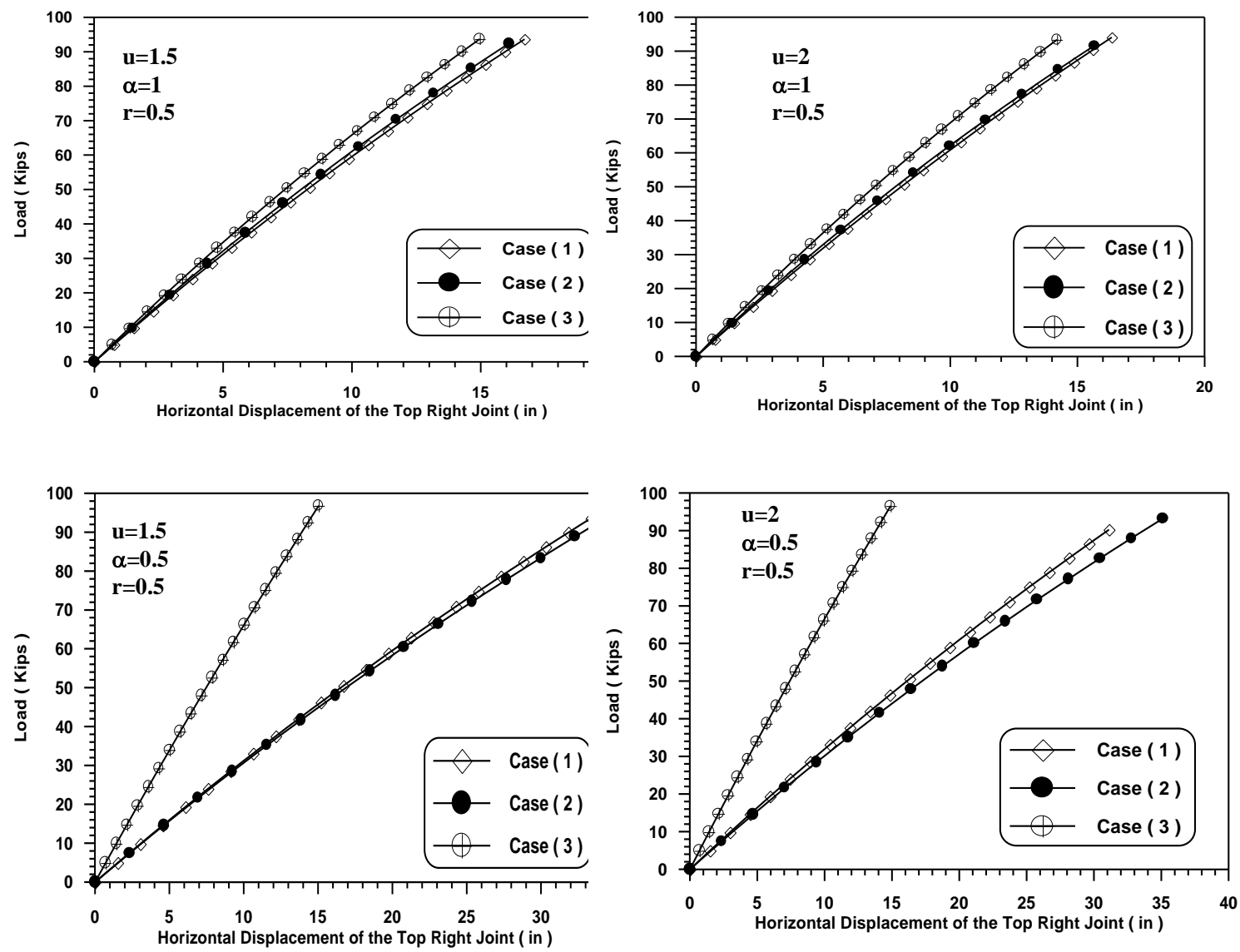

Fig. (21): Load - Displacement Behavior Used for Four Story Frame Case b,c\&d (Rigid Joint). 

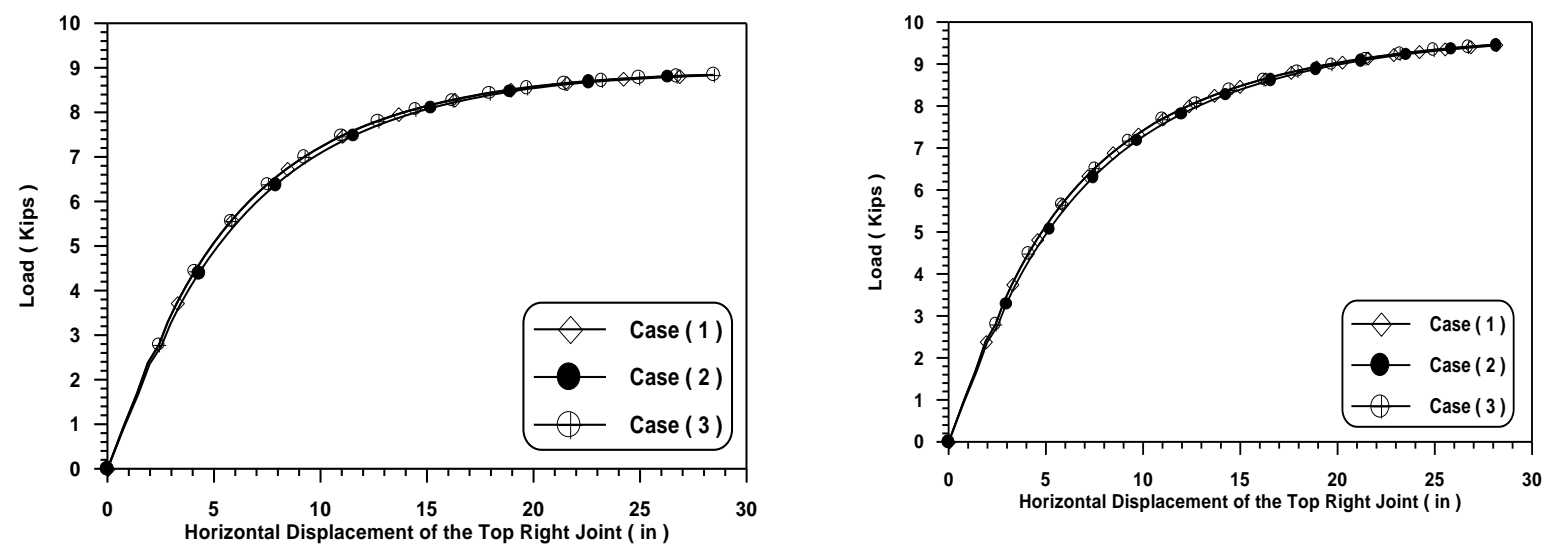

Fig. (22): Load - Displacement Behavior Used for Four Story Frame Case b,c\&d (Flexible Joint).

\section{CONCLUSIONS}

1. This investigation shows that the large displacement elastic behavior of plane steel frames with non-prismatic members subjected to static load and having non-linear connections can be accurately predicted using the beam-column approach of analysis.

2. A comparison between the beam-column approach and finite element approach reveals similar results but the latter requires a larger number of elements than the former, a point which is in favor of the beam-column approach despite the fact that the derivations of the tangent stiffness matrix of the beam-column approach is more complicated than that of the finite element approach.

3. The new modified tangent stiffness matrix which takes into account the two types of nonlinearities at the same time (i.e. geometry and connection) and non-prismatic members efficient in giving accurate results of analysis of different types frames with difference not more than $(0.5 \%)$ compere with the other finite element methods for analysis.

4. The non-prismatic member can be represented by a number of prismatic elements which is considered as the second method of solution in addition to the representing it as a one tapered element (first method) and we will able a good agreement results based on the second method approaches more and more to the solution obtained by first method when the number of elements is increased with difference reaches to the $(5 \%)$.
5. It is shown that a polynomial modeling of the non-linear moment-rotation curve of steel connection gives excellent results with the exact non-linear moment-rotation curve in studying the behavior of steel frames with a difference not more than $(1 \%)$

6. The effect of the flexible connections must be considered in the analysis because it has significant effect on the behavior of the steel structures.

7. The reference load (Fr) must be chosen from (1.3\% to $2 \%)$ of the load at the first limit point.

8. The desired number of iteration for convergence (Jd) can be chosen from (3 to 5), for any type of frames with both rigid and flexible connections.

\section{REFERENCES}

1. Oran, C., "Tangent Stiffness in Plane Frames", Journal of the Structural Division, ASCE, Vol. 99,No.ST6, June, 1973, pp.(973-985).

2. Oran, C., "Geometric Nonlinearity in Nonprismatic Members", Journal of the Structural Division, ASCE, Vol. 100,No.ST7, July, 1974, pp.(14731487).

3. Frye, M.J. and Morris, G.A., "Analysis of Flexibly Connected Steel Frames", Canadian Journal of Civil Engineering, Vol. 2, No. 3, Sept., 1975, pp.(280-291).

4. Haisler, W.E. and Stricklin, J.A., "Displacement Incrementation in Nonlinear Structural Analysis by the Self-Correction Method", International Journal for Numerical Methods in Engineering, Vol. 11, 1977, pp.(3-10).

5. Al-Sarraf, S.z., "Elastic Instability of Frames with Uniformly Tapered Members", The Structural 
Engineer, Vol. 57B, No. 1, March, 1979, pp.(1824).

6. Moncarz, P.D. and Gerstle, K.H., "Steel Frames with Nonlinear Connections", Journal of Structural Division, ASCE, Vol. 107, No.ST8, Aug., 1981, pp.(1427-1441).

7. Moncarz, P.D. and Gerstle, K.H., "Steel Frames with Nonlinear Connections", Journal of Structural Division, ASCE, Vol. 107, No.ST8, Aug., 1981, pp.(1427-1441).

8. Kassimali, A., "Large Deformation Analysis of Elastic-Plastic Frames", Journal of Structural Engineering, ASCE, Vol. 109, No.ST8, August, 1983, pp.(1869-1886).

9. Ang, K.M. and Morris, G.A., "Analysis of ThreeDimensional Frames with Flexible BeamColumn Connections", Canadian Journal of Civil Engineering, Vol. 11, No. 2, June, 1984, pp.(245-254).

10. Chen, W.F. and Lui, E.M., "Columns with End Restraint and Bending in Load and Resistance Design Factor", Engineering Journal, ASCE, 3rd Quarter, Vol. 22, No. 3, 1985, pp.(105-133).

11. $\mathrm{Yu}$, C.H. and Shanmugam, N.E., "Stability of Frames with Semi Rigid Joints", International Journal of Computers and Structures, Vol.23, No.5, 1986, pp.(634-648).

12. Yee, Y.L. and Melchers, R.E., "Moment-Rotation Curves for Bolted Connections", Journal of Structural Engineering, ASCE, Vol. 112, No.3, March, 1986, pp.(615-634).

13. Lui, E.M. and Chen, W.F., "Analysis and Behavior of Flexibly-Jointed Frames", Engineering Structural, Vol. 8,No. 2, April, 1986, pp.(107118).
14. Chen, W.F. and Lui, E.M., "Effects of Joint Flexibility on the Behavior of Steel Frames", Journal of Computers and Structures, Vol. 26, No. 5, September, 1987, pp.(719-732).

15. Clarke, M.j. and Hancock, G.J., "Study of Incremental-Iterative Strategies for Nonlinear Analysis", International Journal for Numerical Methods in Structures, Vol. 29, 1990, pp.(13651391).

16. Wong, M.B. and Tin-Loi, F., "Geometrically Nonlinear Analysis of Elastic Framed Structures", International Journal of Computers and Structures, Vol. 34, No. 4, 1990, pp.(633640).

17. Kassimali, A. and Abbasnia, R., "Large Deformation Analysis of Elastic Space Frames", Journal of Structural Engineering, ASCE, Vol.117, No. 6, July, 1991, pp.(2069-2087).

18. Sadder, S.Z.R., "Large Displacement Elastic-Plastic Stability Analysis of Plane Steel Frames with Nonlinear Connections", M.Sc. thesis, University of Baghdad, December, 1994.

19. Al-Uraiby, B., "Large Displacement and PostBuckling Analysis of Frames with Nonprismatic Members", M.Sc. thesis, University of Babylon, November, 1998.

20. Degertekin S. O. andHayalioglu M. S. , "Design of non-linear semi-rigid steel frames with semirigid column bases", Electronic Journal of Structural Engineering, 4 (2004), p.16.

21. Öztürk A. U. and Seçer M. ,"An Investigation for semi rigid Frames by Different Connection Models" , Mathematical and Computational Applications, Vol. 10, No. 1, 2005, pp. 35-44. 